\title{
Mitochondrial DNA Depletion Syndrome: Mimicker for Hereditary Tyrosinemia
}

\author{
Mahesh Kamate $^{1}$ (D) Saurabh Singh ${ }^{2}$ \\ Received: 1 September 2020 / Accepted: 20 November 2020 / Published online: 26 November 2020 \\ (C) Dr. K C Chaudhuri Foundation 2020
}

To the Editor: Liver-cell failure in infancy and neonatal period has a wide differential diagnosis starting from TORCH infections to rare inborn errors of metabolism. A few of these disorders have biomarkers like increased alpha-fetoprotein in hereditary tyrosinemia and extrahepatic biliary atresia. Mitochondrial DNA depletion syndromes is emerging as an important cause of liver cell failure in infants and can also be associated with increased AFP levels. However, this association is not very well known.

We saw a two-and-half mo old baby girl born of 2 nd degree consanguineous parentage, who presented with liver cell failure, severe failure to thrive and her sibling had died at 5-mo of age with similar complaints. Investigations revealed deranged liver function tests, hypoglycemia, hypertriglyceridemia, normal GGT with raised AFP $16860 \mathrm{ng} / \mathrm{mL}$ (normal range: 323 $\pm 278 \mathrm{ng} / \mathrm{mL}$ ). Abdominal ultrasonography (USG) showed hepatomegaly with generalized increase in echotexture. Urine for metabolic screening (succinyl acetone, fructose and galactose) was negative ruling out tyrosinemia, galactosemia and fructose metabolism defects. For ruling out other metabolic liver disorders, blood was sent for clinical exome sequencing which revealed a homozygous pathogenic (ACMG guidelines) variant in MPV17 gene affecting 3' splice site in intron 5 (c.376-2A > C) that causes MDS-6 (hepatocerebral type). Child was managed with supportive treatment in the form of multivitamins, fresh frozen plasma transfusion, glycemic control with corn-starch diet. At present, the baby is 9-mo-old, has failure to thrive and global developmental delay.

Mahesh Kamate

drmaheshkamate@gmail.com

1 Department of Pediatric Neurology, KAHER's Jawaharlal Nehru Medical College, Belagavi, Karnataka, India

2 Department of Pediatrics, KAHER's Jawaharlal Nehru Medical College, Belagavi, Karnataka, India
Reduction in the mitochondrial DNA (mtDNA) copy number is the molecular hallmark of the mitochondrial DNA depletion syndrome (MDS) [1]. Defects in mitochondrial function can lead to impaired oxidative phosphorylation, increased generation of reactive oxygen species, impairment of other metabolic pathways, and activation of mechanism of cellular death [2]. MPV17 plays role in the structural preservation of the inner mitochondrial membrane, which could in turn control mtDNA maintenance and stability [3]. Verma et al. has reported 2 infants affected with MPV17 gene variants, one of whom had increased AFP like our case [4]. There is no effective therapy for patients with mitochondrial hepatopathies; neurologic involvement often precludes liver transplantation.

With this report we want clinicians to think of mitochondrial hepatopathies as a cause of liver failure in infancy. Raised alphafetoprotein can be a clue to mitochondrial DNA depletion syndromes, after the more common tyrosinemia has been ruled out.

\section{Compliance with Ethical Standards}

Conflict of Interest None.

\section{References}

1. Kim J, Kang E, Kim Y, et al. MPV17 mutations in patients with hepatocerebral mitochondrial DNA depletion syndrome. Mol Genet Metab Rep. 2016;8:74-6.

2. Kliegman RM, Stanton BF, St Geme JW, Schor NF. Nelson Textbook of Paediatrics, $1^{\text {st }}$ Southasia ed. New Delhi: Elsevier; 2017. p. 1958-61.

3. AlSaman A, Tomoum H, Invernizzi F, Zeviani M. Hepatocerebral form of mitochondrial DNA depletion syndrome due to mutation in MPV17 gene. Saudi J Gastroenterol. 2012;18:285-9.

4. Bijarnia-Mahay S, Mohan N, Goyal D, Verma IC. Mitochondrial DNA depletion syndrome causing liver failure. Indian Pediatr. 2014;51(8):666-8.

Publisher's Note Springer Nature remains neutral with regard to jurisdictional claims in published maps and institutional affiliations. 